The role of leadership in developing the innovative manager

By: Elizabeth J. Sander and Arran Caza

Sander, E. J., \& Caza, A. (2015). The role of leadership in developing the innovative manager. In A. Wilkinson, K. Townsend, \& G. Suder (Eds.), Handbook of Research on Managing Managers (pp. 87-103). Cheltenham, UK: Edward Elgar.

This is a draft chapter/article. The final version is available in Handbook of Research on Managing Managers edited by Adrian Wilkinson, Keith Townsend, and Gabriele Suder, published in 2015, Edward Elgar Publishing Ltd. http://dx.doi.org/10.4337/9781783474295

The material cannot be used for any other purpose without further permission of the publisher, and is for private use only.

Abstract:

Innovative managers, those who foster creativity in their teams, are increasingly important as organisations are required to do more with less (Hamel, 2012) as work grows increasingly complex, unpredictable and knowledge-based (Joo et al., 2013). To prosper in this dynamic environment, organisations must adapt and innovate (Agars et al., 2008), and they depend on the creativity of their employees to do so (George, 2007). This need for creativity makes the innovative manager indispensable for many organisations, and therefore a key leadership priority.

Keywords: leadership | managers | innovation | creativity

\title{
Article:
}

Innovative managers, those who foster creativity in their teams, are increasingly important as organisations are required to do more with less (Hamel, 2012) as work grows increasingly complex, unpredictable and knowledge-based (Joo et al., 2013). To prosper in this dynamic environment, organisations must adapt and innovate (Agars et al., 2008), and they depend on the creativity of their employees to do so (George, 2007). This need for creativity makes the innovative manager indispensable for many organisations, and therefore a key leadership priority.

In this chapter, we review existing findings on the qualities and development of innovative managers. We begin with an examination of innovation and how it is affected by differing contexts and organisational conditions. Next, we summarise research on the sources of creativity among employees in order to understand what innovative managers need to provide. Creativity is influenced by a broad range of factors, but our focus here is on those factors suitable for management intervention. We then discuss the three distinctive capacities that distinguish the innovative manager. Finally, we outline the available findings on how leaders can develop and support innovative managers. Table 1 summarises the key elements of the chapter and of managing for innovation. 
Table 1. Summary of the elements involved in leading the management of innovation

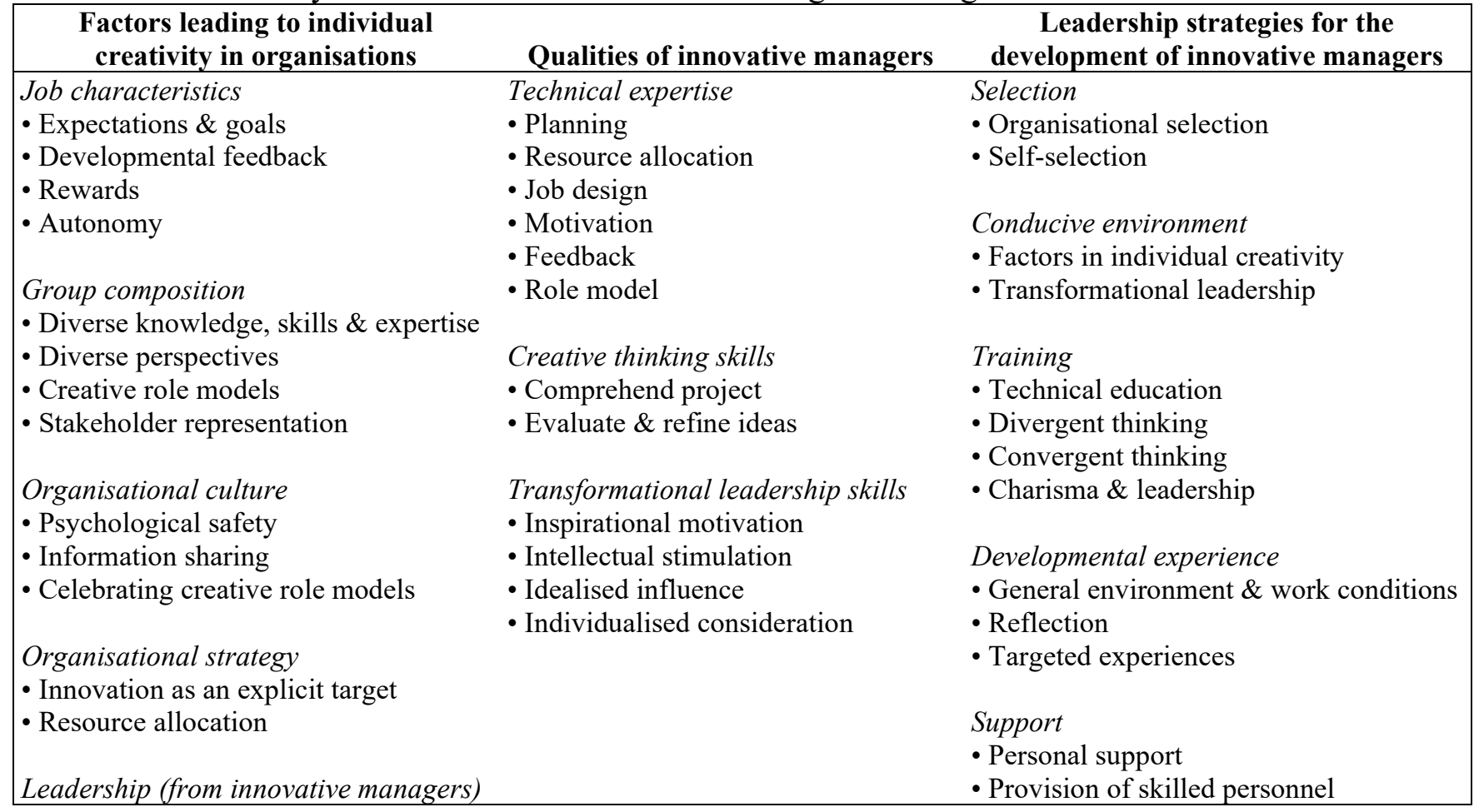

\section{Understanding Innovation}

Organisations seeking innovation rely on creativity from employees, as individual creativity is a vital precursor of innovation (Stenmark et al., 2011). It is important to differentiate between creativity and innovation, which are related but distinct (Anderson et al., 2004). Creativity is the production of novel and useful ideas (Amabile et al., 1996), whereas innovation involves implementing those creative ideas (West and Farr, 1992). In both cases, the novelty is relative to the group in question, so that what is innovative in one organisation may not be in another (Damanpour and Schneider, 2006).

A vivid example of how organisational leadership can foster innovation is provided by Google Inc., which has implemented a range of tools and processes to encourage organisation-wide creativity, including offering Google Cafes, which are designed to encourage interaction within and across teams, and their ' $20 \%$ time' rule, which allows all employees to spend 20 per cent of their work time on projects and ideas of their own choosing (He, 2013). These and similar policies are consistent with the research findings we summarise below, and reflect a shift in thinking away from the traditional view that creativity is the domain of select individuals or departments (e.g. R\&D) to the view that all employees should support creativity (Hamel, 2012). Evidence suggests that leaders are best served by making innovation an organisation-wide endeavour (Hamel, 2012).

Google's innovativeness is typically lauded (Nisen, 2013), on the assumption that innovation is wholly beneficial, but, in fact, innovation may have both positive and negative consequences. 
Innovation is not always a desirable goal. The context of innovation, including not just the new idea, but also the people, organisations, industries, cultures and histories involved, may make innovation less desirable (Inglehart et al., 1998; Janssen et al., 2004; Shane, 1995). Considering the 'dark side' of innovation is beyond the scope of this chapter, however, which follows the research that it summarises, all of which begins from the assumption that innovation is desired. None the less, other perspectives have been offered (e.g. Baucus et al., 2008; Janssen et al., 2004). Similarly, doubts have been raised about the nature and efficacy of leadership (e.g. Alvesson and Sveningsson, 2003), but we follow the research discussed here, which posits leadership's efficacy.

\section{Fostering Creativity Among Employees}

Empirical evidence shows that individual creativity is influenced by a variety of organisational elements, including autonomy, the opportunity to learn from role models, and a supportive organisational culture. In particular, creativity is shaped by six factors: individual differences; job characteristics; group composition; organisational culture; organisational strategy; and leadership (Scott and Bruce, 1994). We summarise evidence concerning each factor below.

\section{Individual Differences}

The first factor, individual differences, has received the most attention in creativity research, and evidence shows that personality, motivation and similar traits contribute to creativity (Mumford, 2003). However, except for their possible use in recruitment, most individual differences are not readily subject to management influence, and so are outside the scope of this chapter. Instead, our focus here is on those factors on which leaders can act.

\section{Job Characteristics}

The way that jobs are designed has a significant effect on employees' outcomes; the organisation and description of tasks can shape creativity (George, 2007). Designing jobs with an expectation that all employees can and should be creative has been found to increase creative behaviour (Unsworth et al., 2005). For example, Shalley and Gilson (2004) found that when jobs provide challenge and complexity, as opposed to simple, routinised work, employees are more likely to increase their focus and persistence, resulting in consideration of broader and potentially more creative alternatives. Further, setting specific creativity goals provides structure and direction in pursuing ideas, which improves outcomes (Shalley and Gilson, 2004). As creativity is a timeconsuming and demanding activity (Gruber and Davis, 1988), access to sufficient time, material resources and people has been shown to promote creativity (Katz and Allen, 1988). In one study of engineers working on new technologies, uninterrupted time was found to be essential (Katz and Allen, 1988). The use of evaluation systems that provide developmental feedback and the use of specific performance rewards create an environment that supports creativity (George and Zhou, 2007). For example, a study of the effect of different types of feedback found that employees who received informational and supportive feedback achieved higher levels of creativity than employees who were given controlling or punitive feedback (Zhou, 1998). Finally, autonomy - freedom in how one works - also contributes to creativity (Amabile, 1998), 
because freedom is necessary for the idea exploration involved in creativity (Shalley and Gilson, 2004).

\section{Group Composition}

While individuals may conceive creative ideas individually, developing and implementing those ideas typically requires a group of people. The membership of that group has a significant influence on its success (Paulus, 2000). Group members can encourage or inhibit creativity. Diverse groups enhance creativity by offering a range of knowledge, skills, expertise and perspectives to be used in generating and developing ideas (Mannix and Neale, 2005). For example, McLeod and Lobel (1992) found that groups with greater ethnic diversity performed better on a creative brainstorming task. The inclusion of diverse individuals can also provide creative role models, which allow individuals to learn about being creative and increase their confidence that they can contribute to creative outcomes (Perry-Smith and Shalley, 2003). Zhou (2003) showed that individuals' creativity was improved by the presence of creative coworkers. In addition, being part of a diverse group provides individuals with more awareness of stakeholder needs, which fosters the development of solutions that are useful (Chiles et al., 2010), which is an important part of creativity.

Organisational Culture

Generating and developing creative ideas is typically unpredictable and frustrating, requiring tenacity to produce a worthwhile outcome (Mumford et al., 2002). As a result, the culture of the organisation has an important role to play in supporting innovation. The term 'culture' has a number of meanings (Denison, 1996), but the most important issue for creativity concerns employees' beliefs about what is valued and appropriate in the organisation. In particular, employees must believe that it is safe for them to be creative, to pursue ideas and take risks without fear of negative consequences (Baer and Frese, 2003).

This feeling of psychological safety is crucial to creativity for three reasons. First, those who feel safe show greater persistence when working on ideas (Frese et al., 1999), resulting in greater creativity (Gist and Mitchell, 1992). Studies have shown that innovativeness is highest in organisations where employees feel safe to undertake challenges and risks (Nystrom, 1990; Abbey and Dickson, 1983). Second, a culture high in psychological safety has been shown to increase the sharing and utilisation of knowledge through information exchange (Gong et al., 2012), enhancing the effectiveness of diverse groups and providing employees with more resources. In one study in a retail chain, Gong and colleagues (2012) found that information increased trust, which in turn increased creativity. Third, psychological safety leads to the development of a work environment where the pursuit of creativity is valued and observable, providing role models and observational learning to enhance creativity (Amabile et al., 1996).

\section{Organisational Strategy}

Individuals' creative endeavours prosper when supported by an organisational strategy that focuses on innovation as an outcome (Parnell et al., 2000), while offering enough flexibility to accommodate its unpredictable nature (Mumford and Hunter, 2005). Having innovation as a 
formal goal supports the culture of innovation; without such support, adequate resources are unlikely to be allocated to creative efforts (Cameron and Caza, 2005; Isaksen et al., 2001). When the organisation focuses on creativity, employees are more likely to communicate more openly, seek ideas from others and experiment with new ways of doing things (Shalley and Gilson, 2004).

\section{Leadership}

Managers' own creativity and the quality of their interactions with employees are strongly correlated with creativity and successful innovation (Tierney et al., 1999; West et al., 2003). For example, a study in the restaurant sector found a significant influence from leaders' creative behaviour on creativity climate and external assessments of organisational creativity (Mathisen et al., 2012). Leadership is critical in both influencing employees to engage in creative actions, and in ensuring those creative ideas develop (Mumford et al., 2002). Leaders can influence job characteristics by setting goals, establishing expectations of creativity, and providing developmental feedback. Furthermore, managers can affect the composition of project groups and offer opportunities for employees to interact with diverse others. Managers enact organisational strategy and can support a culture of psychological safety by role-modelling creative behaviour, removing obstacles to the innovation process, and championing ideas. Research shows that leaders may even be able to foster creativity by shaping individual differences: leadership can increase employees' intrinsic motivation and confidence (Amabile et al., 1996). As these examples show, it seems hard to overstate the importance of leadership in the creative process. The required qualities of innovative managers are the focus of the next section.

\section{Innovative Managers}

Managerial support for creativity is crucial (Jung et al., 2003). A recent meta-analysis of 80 studies found consistent evidence of the positive relationship between leadership and creative behaviour (Hammond et al., 2011). To provide the necessary leadership for employee creativity, innovative managers need to be good managers in general, and must also have certain distinctive qualities (Ligon et al., 2011 ). In addition to performing standard managerial functions, innovative managers must supervise the innovation process from initiation, where ideas are first generated, to implementation, where new processes or products are adopted (Axtell et al., 2000). The nature of managing innovation therefore requires additional skills beyond those necessary for general management, and demands that managers of creative efforts play distinctive roles.

Extensive research has established the qualities required for general management, such as communication skills, planning and directing (Yukl, 1989). As such, we will not review these qualities here, but instead keep our focus on the additional qualities associated with leading innovative efforts. Evidence suggests that innovative managers benefit from three additional skills beyond general management capacity: technical expertise; creative thinking skills; and transformational leadership.

Technical Expertise 
In routine situations, managers may effectively supervise employees without a deep understanding of their work. The same is not true for innovation: innovative managers need domain knowledge in the area of innovation (Ligon et al., 2011). In fact, leader expertise is the best predictor of groups' innovation performance (Mumford et al., 2007). For example, Andrews and Farris (1967) found that leaders' technical skills were better predictors of scientists' creative performance than the ability to motivate, to maintain relationships or to provide autonomy. Without sufficient expertise, managers cannot understand the work well enough to plan, allocate resources or appropriately influence job characteristics (Yukl and Heaton, 2002). Expertise also contributes to the manager's credibility among employees (Carmeli et al., 2013), which has several important implications. Credible managers are more effective at implementing organisational strategy and they increase employees' motivation (Mumford et al., 2007). Expert managers provide better direction and feedback, and their credibility makes employees more likely to attend to that feedback (Mumford, 2003). Also, credibility allows managers to serve as role models, which supports feelings of psychological safety and provides opportunities for learning (Mumford, 2003).

\section{Creative Thinking Skills}

Managers' ability to understand and participate in the creative process will influence their ability to manage for innovation. Even when managers are not required personally to generate creative ideas, their leadership depends on their ability to comprehend the overall project (O'Connor, 1998), as well as to evaluate and refine the ideas of others (Basadur et al., 2000). Managers' personal creativity influences that of subordinates because managers must make sense of the ideas and issues being presented and provide feedback that leads to successful development (Basadur et al., 2000). Creative leaders have been found to directly influence creativity among their employees through the provision of a supportive work climate, as well as acting as both a role model and an inspiration (de Jong and Den Hartog, 2007; Jaussi and Dionne, 2003; Mathisen et al., 2012).

\section{Transformational Leadership}

Transformational leadership comprises four separate but interdependent components: inspirational motivation; intellectual stimulation; idealised influence; and individualised consideration (Bass and Riggio, 2006). All these components can influence employee creativity (Gumusluoglu and Ilsev, 2009; Sosik et al., 1998). Inspirational motivation refers to the leader's ability to create compelling visions and communicate these effectively to followers (Bass and Riggio, 2006). How leaders define and present the mission of the innovative project will influence how followers think about it, and their level of engagement in the project (Mumford et al., 2007). Effectively communicating a project vision motivates followers and enhances creativity (Mumford et al., 2002). If followers are motivated by the project goal and see the value in its success, they are more likely to provide the effort and persistence that creativity requires.

Intellectual stimulation concerns the leader's ability and willingness to question assumptions, challenge the status quo and pursue novel solutions (Bass and Riggio, 2006). It is the transformational leadership capacity most obviously related to creativity, as it involves motivating and challenging followers to do things differently (Sosik et al., 1998). Through 
intellectual stimulation, transformational leaders foster a culture of psychological safety by allowing followers to experiment and by accepting their inevitable failures (Carmeli et al., 2013).

Idealised influence is the effect that leaders have through personal charisma, serving as role models and motivating followers to be like them (Bass and Riggio, 2006). When leaders model appropriate behaviours by engaging in collaboration, sharing knowledge freely, and applying their own creative skills, they motivate followers to do the same, increasing creativity (Carmeli et al., 2013). Leaders may have a particularly powerful effect when they role-model and support information sharing. Sharing and combining information is a vital part of creativity (Mumford and Hunter, 2005), but it is not something that most employees are inclined to do. Employees may feel possessive of their knowledge, lack confidence in their ideas, or have concerns about the consequences of sharing (Von Krogh, 2003), which is why information sharing is often so poor (Storey and Barnett, 2000).

Individualised consideration involves the leader's role as a mentor and guardian for followers, helping them to perform and giving them what they need as individuals (Bass and Riggio, 2006). Providing followers with the specific support and resources they need contributes directly to their creative performance (Mumford and Hunter, 2005). Individualised consideration may also have a less direct but more powerful influence through mentoring. Mentors are strongly associated with creative success through their ability to provide encouragement, support, expertise and interpersonal contacts (Bennetts, 2004; Torrance, 1983).

\section{Developing Innovative Managers}

Having reviewed evidence about the distinctive qualities that innovative managers require, we tum our attention to what the literature reveals about how senior leaders can develop and support those qualities in managers. Consistent with recent models of leadership training (Mumford et al., 2007; Mumford and Manley, 2003) and adult learning (Baltes, 1997; Schulz and Heckhausen, 1996), we consider five aspects of managerial development: selecting innovative managers; providing a conducive environment; providing specific training; facilitating appropriate developmental experiences; and supporting managers' efforts.

\section{Selection}

In selecting potential innovative managers, two types of selection are relevant: organisational selection and self-selection (Mumford et al., 2007). Clearly, it is important that organisations select appropriate individuals for the role of innovative manager, but evidence shows that organisational selection is probably not sufficient. Self-selection is an equally important matter. Successful managers of innovation have been shown to view themselves simultaneously as leaders, managers and entrepreneurs (de Jong and Den Hartog, 2007). Their expert identity and affiliation with their profession is typically their greatest source of satisfaction (Mumford et al., 2002). Ironically, the sort of creative technical expert that is most likely to be chosen as an innovative manager may also be the most likely to shy away from the role. Evidence suggests that innovative managers will be more successful when allowed to choose the role themselves, rather than being commanded into it (Mumford et al., 2005). 


\section{Conducive Environment}

Earlier, we noted that the organisational environment powerfully influences individual creativity, and also that managers' creativity influences employee creativity and subsequent innovation. As such, managers working in appropriate environments will be better able to lead innovation. For example, just as employees need a feeling of psychological safety, so do managers (Cameron and Caza, 2005). All the factors we discussed previously will thus have an additional effect through their influence on managers' creativity. Moreover, the effect of these environmental factors may go beyond managers' creativity to influence other important qualities. For example, the experience of autonomy at work is an important antecedent of transformational leadership behaviour (Trepanier et al., 2013).

In light of the previously mentioned issues concerning self-selection, senior leaders' transformational leadership skills may also be particularly important. Since creative people usually identify more with their work than with their organisation, they may see a managerial role as taking time away from the creating they love (Ligon et al., 2011). Transformational leadership (as described in the previous section) may overcome this resistance. Transformational leaders provide the individual with the specific tools and support they need for challenging tasks, they imbue the task at hand with meaning and purpose, and they help followers to shift towards more collective or team-oriented thinking (Bass and Riggio, 2006). Innovative managers facilitate their employees' creativity, and thus play an essential role in the collective creative process. However, to fulfil and value this role, they must adopt a more collective perspective; they must change their own thinking first (Caza and Quinn, 2007). Senior-level transformational leadership may guide potential innovative managers towards this perspective.

Training

All the qualities required by innovative managers can be improved by specific training. The most apparent of these is the ability of training to improve technical expertise, since it is most closely associated with traditional education. In addition to formal training, technical expertise may also be improved through appropriate development experiences, as described later.

However, managers' creative thinking skills can also be improved through training. Although there is a commonly held belief that people need to be born creative, and while it is true that individual traits make a substantial contribution to creativity (Mumford, 2003), it is also true that creativity can be intentionally increased. In particular, creativity benefits from training in both divergent and convergent thinking (Basadur et al., 1982). Divergent thinking refers to seeking variety (Runco, 1991). It requires the ability to generate many ideas of a diverse nature without applying judgements about their quality or feasibility, and is the most important predictor of creative performance (Basadur et al., 2000). At the same time, innovative managers should also be trained in evaluation, or convergent thinking (Runco, 1991). After many possibilities have been generated, it is important to evaluate them and seek a preferred solution. In a study of 112 managers from a large international consumer goods company, Basadur and colleagues (2000) found that training managers in the process of creativity increased both their divergent and convergent thinking skills. 
Training can also enhance innovative managers' transformational leadership. For example, managers are better able to articulate the organisational vision and to align actions with it when they are kept apprised of strategic intent (West et al., 2003). Similarly, training in communication skills supports many aspects of transformational leadership (Fiol et al., 1999). Moreover, in addition to benefits from training in the basic skills and information needed by leaders, research also indicates that training can directly improve individuals' interpersonal power and charisma. In particular, research has shown that teaching managers to make changes in how they speak can increase their personal charisma (Antonakis et al., 2011).

\section{Developmental Experience}

Although formal training contributes to the development of innovative managers, those managers' on-the-job experiences appear to be far more influential. Personal experience is crucially important for adult learning in general (McCall, 2010), but seems particularly so for the development of innovative managers because of the complexity and interdependence of the abilities they need to develop (Ligon et al., 2011). All aspects of managers' organisational experiences can shape their effectiveness as innovative managers. For example, their feelings of autonomy at work will influence their creativity (Amabile, 1998) and their transformational leadership (Trepanier et al., 2012). Similarly, the attitudes and behaviours of peers in the organisation will influence a manager's capacity for leadership (Bommer et al., 2004).

\section{Support}

The final consideration, of providing support, is an important matter that is often overlooked in practice and in the literature. The broad range of skills required of innovative managers may mean that it is sometimes not possible for an otherwise good manager to develop them all. For example, to champion employee creativity, innovative managers must overcome two distinct types of resistance: resistance from ignorance of the innovation's potential and resistance from the general tendency to resist change. Because the two types of resistance are different, they require different responses (Hauschildt and Kirchmann, 2001), contributing to the great breadth of qualities that an innovative manager requires (Howell and Boies, 2004). It has been argued that some of the qualities required may oppose each other (Kotter, 2001), and so it may not be possible for an innovative manager to display all the required qualities, particularly at early career stages. As such, senior leaders should be prepared to support those areas where the manager needs assistance (Mumford et al., 2002).

\section{Conclusion and Future Directions}

Employee creativity and the innovation it involves have become increasingly important in many contexts, which has made the development of managers who can champion and nurture innovation a key leadership priority. This chapter reviewed existing findings on the role and function of leadership in developing such innovative managers. In particular, we discussed the factors that influence employee creativity, the distinctive qualities that innovative managers require to support those factors, and the role of senior leadership in developing such managers. The result is a framework that can be used to understand innovative management and to intervene in its development. 
Another result of reviewing and integrating the available evidence is to highlight areas that require further development. This chapter was structured in a three-level analysis: among employees, we examined the antecedents of individual creativity; at the managerial level, we examined the qualities required to support creative employees; and, finally, we considered what is needed at the senior leadership level to develop innovative managers. The research evidence on these matters becomes increasingly scarce as we move up those levels. That is, we know far less about what it takes to develop an innovative manager than we do about what it takes to foster employee creativity. None the less, each of the three levels offers important directions for future research.

At the employee level, there is a large body of evidence on the influence of individual differences, and a growing one on the effect of one's social environment. What remains to be better understood is the role of the physical work environment (Shalley and Gilson, 2004). Ceylan and colleagues (2008) suggested that many characteristics of the physical environment, such as colours, lighting, construction materials and spatial arrangement, may influence creativity. Consistent with these claims, preliminary evidence suggests that the design and layout of the physical work environment can support or inhibit aspects of the creative process, including creative thinking, interpersonal interaction and the transfer of knowledge (Martens, 2011). However, the mechanisms of these effects remain to be explored (Davis et al., 2011). Understanding the role of the physical environment in creativity is an important future direction for research at the individual level.

At the level of the innovative manager, there is a similar need to better understand the mechanisms by which creativity and innovation are fostered. While there is strong evidence on the importance of the innovative manager's role in the creative process (Hammond et al., 2011), it is far less clear exactly how that role is played, and in some cases there even appear to be conflicting findings (Denti and Remlin, 2012). For example, the relationship between leadership and employee empowerment in fostering creative outcomes is uncertain, with different studies suggesting moderation, mediation or contingency results (Gumusluoglu and Ilsev, 2009; Pieterse et al., 2010). More research and greater theoretical clarity are needed to understand the processes by which managers influence employees' creativity.

In terms of understanding how best to develop innovative managers, there is little direct research evidence, but it is certainly needed. In addition to being good managers in general, innovative managers also need to be able to handle the multitude of activities and behaviours specific to the innovation process, making theirs a uniquely demanding role. The current literature on leadership development provides scant direction for fostering such managers. In fact, the leadership development literature in general is only at an early stage (Caza and Rosch, 2013). For example, although transformational leadership is one of the best-known and most established models in leadership theory, even there, research has only just begun to examine environmental and intervention-based antecedents (Bommer et al., 2004). Given the strong and growing need for innovative managers, empirical research in this area is urgently required.

\section{References}


Abbey, A. and Dickson, J.W. (1983). 'R\&D work climate and innovation in semiconductors', Academy of Management Journal, 26, 362-8.

Agars, M.D., Kaufman, J.C. and Locke, T.R. (2008). 'Social influence and creativity in organizations: a multi-level lens for theory, research, and practice', Research in MultiLevel Issues, 1, 3---61.

Alvesson, M. and Sveningsson, S. (2003). 'The great disappearing act: difficulties in doing 'leadership", The Leadership Quarterly, 14, 359-81.

Amabile, T.M. (1998). How to Kill Creativity, Boston, MA: Harvard Business School Publishing.

Amabile, T.M., Conti, R., Coon, H., Lazenby, J. and Herron, M. (1996). 'Assessing the work environment for creativity', Academy of Management Journal, 39, 1154-84.

Anderson, N., De Dreu, C.K.W. and Nijstad, B.A. (2004). 'The routinization of innovation research: a constructively critical review of the state-of-the-science', Journal of Organizational Behavior, 25, 147-73.

Andrews, F.M. and Farris, G.F. (1967). 'Supervisory practices and innovation in scientific teams', Personnel Psychology, 20, 497-515.

Antonakis, J., Fenley, M. and Liechti, S. (2011). 'Can charisma be taught? Tests of two interventions', Academy of Management Learning \& Education, 10, 374-96.

Axtell, C.M., Holman, D.J., Unsworth, K.L., Wall, T.D., Waterson, P.E. and Harrington, E. (2000). 'Shopfloor innovation: facilitating the suggestion and implementation of ideas', Journal of Occupational and Organizational Psychology, 73, 265-85.

Baer, M. and Frese, M. (2003). 'Innovation is not enough: climates for initiative and psychological safety, process innovations, and firm performance', Journal of Organizational Behavior, 24, 45-68.

Baltes, P.B. (1997). 'On the incomplete architecture of human ontogeny: selection, optimization, and compensation as foundation of developmental theory', American Psychologist, 52, 366-80.

Basadur, M., Graen, G.B. and Green, S.G. (1982). 'Training in creative problem solving: effects on ideation and problem finding and solving in an industrial research organization', Organizational Behavior and Human Performance, 30, 41-70.

Basadur, M., Runco, M.A. and Vega, L. (2000). 'Understanding how creative thinking skills, attitudes and behaviors work together: a causal process model', The Journal of Creative Behavior, 34, 77-100.

Bass, B.M. and Riggio, R.E. (2006). Transformational Leadership, Mahwah, NJ: Lawrence Erlbaum Associates.

Baucus, M.S., Norton Jr, W.I., Baucus, D.A. and Human, S.E. (2008). 'Fostering creativity and innovation without encouraging unethical behavior', Journal of Business Ethics, 81, 97115. 
Bennetts, C. (2004). 'The flight of the phoenix: using hermeneutics to interpret the role of the mentor in the creative cycle', International Journal of Lifelong Education, 23, 367-83.

Bommer, W.H., Rubin, R.S. and Baldwin, T.T. (2004). 'Setting the stage for effective leadership: antecedents of transformational leadership behavior', The Leadership Quarterly, 15, 195210.

Cameron, K. and Caza, A. (2005). 'Developing strategies and skills for responsible leadership', in J.P. Doh and S.A. Stumpf (eds), Handbook on Responsible Leadership and Governance in Global Business, Cheltenham, UK and Northampton, MA, USA: Edward Elgar, pp.87111.

Carmeli, A., Gelbard, R. and Reiter-Palmon, R. (2013). 'Leadership, creative problem-solving capacity, and creative performance: the importance of knowledge sharing', Human Resource Management, 52, 95-121.

Caza, A. and Quinn, R.E. (2007). 'Entering the fundamental state of leadership', in S. Piderit, R. Fry and D. Cooperrider (eds), Handbook of Transformative Cooperation: New Designs and Dynamics, Stanford, CA: Stanford University, pp.170-91,

Caza, A. and Rosch, D.M. (2013). 'An exploratory examination of students' pre-existing beliefs about leadership', Studies in Higher Education, 1-13.

Ceylan, C., Dul, J. and Aytac, S. (2008). 'Can the office environment stimulate a manager's creativity?', Human Factors and Ergonomics in Manufacturing \& Service Industries, 18, 589-602.

Chiles, T.H., Tuggle, C.S., McMullen, J.S., Bierman, L. and Greening, D.W. (2010). 'Dynamic creation: extending the radical Austrian approach to entrepreneurship', Organization Studies, 31, 7-46.

Damanpour, F. and Schneider, M. (2006). 'Phases of the adoption of innovation in organizations: effects of environment, organization and top managers', British Journal of Management, 17, 215-36.

Davis, M.C., Leach, D.J. and Clegg, C.W. (2011). 'The physical environment of the office: contemporary and emerging issues', International Review of Industrial and Organizational Psychology, 26, 193-237.

De Jong, J.P. and Den Hartog, D.N. (2007). 'How leaders influence employees' innovative behaviour', European Journal of Innovation Management, 10, 41-64.

Denison, D.R. (1996). 'What is the difference between organizational culture and organizational climate? A native's point of view on a decade of paradigm wars', Academy of Management Review, 21, 619-54.

Denti, L. and Hemlin, S. (2012). 'Leadership and innovation in organizations: a systematic review of factors that mediate or moderate the relationship', International Journal of Innovation Management, 16 (3), 1240007-1-1240007-20.

Fiol, C.M., Harris, D. and House, R. (1999). 'Charismatic leadership: strategies for effecting social change', The Leadership Quarterly, 10, 449-82. 
Frese, M., Teng, E. and Wijnen, C.J. (1999). 'Helping to improve suggestion systems: predictors of making suggestions in companies', Journal of Organizational Behavior, 20, 1139-55.

George, J.M. (2007). 'Creativity in organizations', The Academy of Management Annals, 1, 43977.

George, J.M. and Zhou, J. (2007). 'Dual tuning in a supportive context: joint contributions of positive mood, negative mood, and supervisory behaviors to employee creativity', Academy of Management Journal, 50, 605-22.

Gist, M.E. and Mitchell, T.R. (1992). 'Self-efficacy: a theoretical analysis of its determinants and malleability', Academy of Management Review, 17, 183-211.

Gong, Y., Cheung, S.-Y., Wang, M. and Huang, J.-C. (2012). 'Unfolding the proactive process for creativity integration of the employee proactivity, information exchange, and psychological safety perspectives', Journal of Management, 38, 1611-33.

Gruber, H.E. and Davis, S.N. (1988). 'Inching our way up Mount Olympus: the evolving-systems approach to creative thinking', in J.J. Sternberg (ed.), The Nature of Creativity: Contemporary Psychological Perspectives, Cambridge, UK. Cambridge University Press, pp.243-70.

Gumusluoglu, L. and Ilsev, A. (2009). 'Transformational leadership, creativity, and organizational innovation', Journal of Business Research, 62, 461-73.

Hamel, G. (2012). What Matters Now: How to Win in a World of Relentless Change, Ferocious Competition, and Unstoppable Innovation, San Francisco, CA: John Wiley \& Sons.

Hammond, M.M., Neff, N.L., Farr, J.L., Schwall, A.R. and Zhao, X. (2011). 'Predictors of individual-level innovation at work: a meta-analysis', Psychology of Aesthetics, Creativity, and the Arts, 5 (1), 90-105.

Hauschildt, J. and Kirchmann, E. (2001). 'Teamwork for innovation - the 'troika' of promoters', $R \& D$ Management, 31, 41-9.

He, L. (2013). 'Google's secrets of innovation: empowering its employees', Forbes. URL http://www.forbes.com/sites/laurahe/2013/03/29/googles-secrets-of-innovationempowering-its-employees/ (accessed 17 July 2014).

Howell, J.M. and Boies, K. (2004). 'Champions of technological innovation: the influence of contextual knowledge, role orientation, idea generation, and idea promotion on champion emergence', The Leadership Quarterly, 15, 123-43.

Inglehart, R., Basanez, M. and Moreno, A.M. (1998). Human Values and Beliefs: A crosscultural sourcebook: political, religious, sexual, and economic norms in 43 societies; findings from the 1990-1993 world value survey, Ann Arbor, MI: University of Michigan Press.

Isaksen, S.G., Lauer, K.J., Ekvall, G. and Britz, A. (2001). 'Perceptions of the best and worst climates for creativity: preliminary validation evidence for the situational outlook questionnaire', Creativity Research Journal, 13, 171-84. 
Janssen, O., van de Vliert, E. and West, M. (2004). 'The bright and dark sides of individual and group innovation: a Special Issue introduction', Journal of Organizational Behavior, 25, 129-45.

Jaussi, K.S. and Dionne, S.D. (2003). 'Leading for creativity: the role of unconventional leader behavior', The Leadership Quarterly, 14, 475-98.

Joo, B.-K.B., McLean, G.N. and Yang, B. (2013). 'Creativity and human resource development: an integrative literature review and a conceptual framework for future research', Human Resource Development Review, 12, 390-421.

Jung, D.I., Chow, C. and Wu, A. (2003). 'The role of transformational leadership in enhancing organizational innovation: hypotheses and some preliminary findings', The Leadership Quarterly, 14, 525-44.

Katz, R. and Allen, T.J. (1988). 'Investigating the not invented here (NIH) syndrome: a look at the performance, tenure, and communication patterns of $50 \mathrm{R} \& \mathrm{D}$ Project Groups', $R \& D$ Management, 12 (1), 7-20.

Kotter, J.P. (2001). 'What leaders really do', Harvard Business Review, 79, 85-98.

Ligon, G.S., Wallace, J.H. and Osburn, H.K. (2011). 'Experiential development and mentoring processes for leaders for innovation', Advances in Developing Human Resources, 13, 297-317.

Mannix, E. and Neale, M.A. (2005). 'What differences make a difference? The promise and reality of diverse teams in organizations', Psychological Science in the Public Interest, 6, $31-55$.

Martens, Y. (2011). 'Creative workplace: instrumental and symbolic support for creativity', Facilities, 29, 63-79.

Mathisen, G.E., Einarsen, S. and Mykletun, R. (2012). 'Creative leaders promote creative organizations', International Journal of Manpower, 33, 367-82.

McCall, M.W. (2010). 'Recasting leadership development', Industrial and Organizational Psychology, 3, 3-19.

McLeod, P.L. and Lobel, S.A. (1992). 'The effects of ethnic diversity on idea generation in small groups', in Academy of Management Proceedings, London: Academy of Management, pp.227-31.

Mumford, M.D. (2003). 'Where have we been, where are we going? Taking stock in creativity research', Creativity Research Journal, 15, 107-20.

Mumford, M.D. and Hunter, S.T. (2005). 'Innovation in organizations: a multi-level perspective on creativity', Research in Multi-Level Issues, 4, 9-73.

Mumford, M.D. and Manley, G.G. (2003). 'Putting the development in leadership development: implications for theory and practice', in S.E. Murphy and R. Riggio (eds), The Future of Leadership Development, Mahwah, NJ: Lawrence Erlbaum Associates, pp. 237-61. 
Mumford, M.D., Scott, G.M., Gaddis, B. and Strange, J.M. (2002). 'Leading creative people: orchestrating expertise and relationships', The Leadership Quarterly, 13, 705-50.

Mumford, M.D., Hunter, S.T., Eubanks, D.L., Bedell, K.E. and Murphy, S.T. (2007). 'Developing leaders for creative efforts: a domain-based approach to leadership development', Human Resource Management Review, 17, 402-17.

Nisen, M. (2013). 'Here are the 50 most innovative companies in the world', Business Insider Australia. URL http://www.businessinsider.com.au/most-innovative-companies-in-theworld-2013-9 (accessed 17 July 2014).

Nystrom, H. (1990). Organizational Innovation, Chichester, UK: Wiley.

O'Connor, G.C. (1998). 'Market learning and radical innovation: a cross case comparison of eight radical innovation projects', Journal of Product Innovation Management, 15, 151-66.

Parnell, J.A., Lester, D.L. and Menefee, M.L. (2000). 'Strategy as a response to organizational uncertainty: an alternative perspective on the strategy-performance relationship', Management Decision, 38, 520-30.

Paulus, P. (2000). 'Groups, teams, and creativity: the creative potential of idea-generating groups', Applied Psychology, 49, 237-62.

Perry-Smith, J.E. and Shalley, C.E. (2003). 'The social side of creativity: a static and dynamic social network perspective', Academy of Management Review, 28, 89-106.

Pieterse, A.N., Van Knippenberg, D., Schippers, M. and Stam, D. (2010). 'Transformational and transactional leadership and innovative behavior: the moderating role of psychological empowerment', Journal of Organizational Behavior, 31, 609-23.

Runco, M.A. (1991). Divergent Thinking, Westport, CT: Ablex Publishing.

Schulz, R. and Heckhausen, J. (1996). 'A life span model of successful aging', American Psychologist, 51, 702-14.

Scott, S.G. and Bruce, R.A. (1994). 'Determinants of innovative behavior: a path model of individual innovation in the workplace', Academy of Management Journal, 37, 580-607.

Shalley, C.E. and Gilson, L.L. (2004). 'What leaders need to know: a review of social and contextual factors that can foster or hinder creativity', The Leadership Quarterly, 15, 3353.

Shane, S. (1995). 'Uncertainty avoidance and the preference for innovation championing roles', Journal of International Business Studies, 26, 47-68.

Sosik, J.J., Kahai, S.S. and Avolio, B.J. (1998). 'Transformational leadership and dimensions of creativity: motivating idea generation in computer-mediated groups', Creativity Research Journal, 11, 111-21.

Stenmark, C.K., Shipman, A.S. and Mumford, M.D. (2011). 'Managing the innovative process: the dynamic role of leaders', Psychology of Aesthetics, Creativity, and the Arts, 5 (1), $67-$ 80 . 
Storey, J. and Barnett, E. (2000). 'Knowledge management initiatives: learning from failure', Journal of Knowledge Management, 4, 145-56.

Tierney, P., Farmer, S.M. and Graen, G.B. (1999). 'An examination of leadership and employee creativity: the relevance of traits and relationships', Personnel Psychology, 52, 591-620.

Torrance, E.P. (1983). 'Role of mentors in creative achievement', Creative Child \& Adult Quarterly, 8 (1), 8-15.

Trepanier, S.-G., Fernet, C. and Austin, S. (2013). 'The moderating role of autonomous motivation in the job demands-strain relation: a two sample study', Motivation and Emotion, 37, 93-105.

Unsworth, K.L., Wall, T.D. and Carter, A. (2005). 'Creative requirement: a neglected construct in the study of employee creativity?', Group \& Organization Management, 30, 541-60.

Von Krogh, G. (2003). 'Knowledge sharing and the communal resource', in M. Easterby-Smith and M.A. Lyles (eds), Handbook of Organizational Learning and Knowledge Management, New York: Wiley Blackwell, pp. 372-92.

West, M.A. and Farr, J.L. (1992). Innovation and Creativity at Work: Psychological and Organizational Strategies, Chichester, UK: Wiley.

West, M.A., Borrill, C.S., Dawson, J.F., Brodbeck, F., Shapiro, D.A. and Haward, B. (2003). 'Leadership clarity and team innovation in health care', The Leadership Quarterly, 14, 393-410.

Yuki, G. (1989). 'Managerial leadership: a review of theory and research', Journal of Management, 15, 251-89.

Yuki, G. and Heaton, H. (2002). Leadership in Organizations, Englewood Cliffs, NJ: PrenticeHall.

Zhou, J. (1998). 'Feedback valence, feedback style, task autonomy, and achievement orientation: interactive effects on creative performance', Journal of Applied Psychology, 83, 261-76.

Zhou, J. (2003). 'When the presence of creative coworkers is related to creativity: role of supervisor close monitoring, developmental feedback, and creative personality', Journal of Applied Psychology, 88, 413-22. 